\title{
Dynamic Environmental Regulation Threshold Effect of Technical Progress on Green Total Factor Energy Efficiency:Evidence from China
}

\section{Ge Li}

Huazhong University of Science and Technology - Main Campus: Huazhong University of Science and Technology

Da Gao ( $\sim$ gaoda@hust.edu.cn )

Huazhong University of Science and Technology https://orcid.org/0000-0002-3078-8316

Yi Li

Huazhong University of Science and Technology - Main Campus: Huazhong University of Science and Technology

\section{Research Article}

Keywords: Technical innovation, Environmental regulation, Green total factor energy efficiency, Dynamic panel threshold model

Posted Date: May 25th, 2021

DOI: https://doi.org/10.21203/rs.3.rs-463674/v1

License: (c) (i) This work is licensed under a Creative Commons Attribution 4.0 International License. Read Full License 


\title{
Title page
}

\section{Dynamic environmental regulation threshold effect of technical progress on Green Total Factor Energy Efficiency: Evidence from China}

\begin{abstract}
Sustainability is a strategic choice for the transition to a green economy in China. Improving green total factor energy efficiency (GTFEE) is the key to realizing the dual targets of energy saving and economic growth. This paper assesses the nonlinear influence of environmental regulation (ER) on technical innovation (TI) affecting GTFEE by establishing a dynamic panel threshold model using panel data of 271 prefecture-level cities in China from 2004-2016. Meanwhile, a system GMM approach is used to verify the channels through which TI affects GTFEE. Finally, the spatial and temporal characteristics of TI affecting GTFEE are analyzed from the perspective of ER. The empirical results are as follows: (1) TI can significantly improve GTFEE, and there is a threshold characteristic of this improvement effect, when ER is above the threshold value, TI has a greater improvement effect on GTFEE. (2) Besides directly influencing GTFEE through green technical innovation effect, TI can also indirectly influence GTFEE via channels such as economic growth effect, industrial structure upgrading effect and foreign investment effect, and the indirect influence channels show ER heterogeneity. (3) The number of cities crossing the threshold of ER in China increases year by year, which helps TI play a role in improving GTFEE, but there are still a small number of cities that do not cross the threshold during the sample period, which should attract the attention of local governments.
\end{abstract}

Key words: Technical innovation; Environmental regulation; Green total factor energy efficiency ; Dynamic panel threshold model

First author: $\quad$ Ge Li $\quad$ E-mail: lige@hust.edu.cn

Huazhong University of Science and technology Wuhan city, Hubei Province in China

Corresponding author : Da Gao School of economics in Huazhong University of Science and technology Wuhan city, Hubei Province in China

E-mail: gaoda@hust.edu.cn

Tel: $\quad+8613387625013$

Adress: Room 515, Building Tianjiabing, No.1037, Luoyu Road, Hongshan District, Wuhan, Hubei, P.R.China

Co-author: $\quad$ Li Yi E-mail: ellie@hust.edu.cn

Huazhong University of Science and technology Wuhan city, Hubei Province in China 


\section{Dynamic environmental regulation threshold effect of technical progress on Green Total Factor Energy Efficiency: Evidence from China}

Abstract: Sustainability is a strategic choice for the transition to a green economy in China. Improving green total factor energy efficiency (GTFEE) is the key to realizing the dual targets of energy saving and economic growth. This paper assesses the nonlinear influence of environmental regulation (ER) on technical innovation (TI) affecting GTFEE by establishing a dynamic panel threshold model using panel data of 271 prefecture-level cities in China from 2004-2016. Meanwhile, a system GMM approach is used to verify the channels through which TI affects GTFEE. Finally, the spatial and temporal characteristics of TI affecting GTFEE are analyzed from the perspective of ER. The empirical results are as follows: (1) TI can significantly improve GTFEE, and there is a threshold characteristic of this improvement effect, when ER is above the threshold value, TI has a greater improvement effect on GTFEE. (2) Besides directly influencing GTFEE through green technical innovation effect, TI can also indirectly influence GTFEE via channels such as economic growth effect, industrial structure upgrading effect and foreign investment effect, and the indirect influence channels show ER heterogeneity. (3) The number of cities crossing the threshold of ER in China increases year by year, which helps TI play a role in improving GTFEE, but there are still a small number of cities that do not cross the threshold during the sample period, which should attract the attention of local governments.

Key words: Technical innovation; Environmental regulation ; Green total factor energy efficiency ; Dynamic panel threshold model

\section{Introduction}

China's economy saw a continuous rise in the past few decades, but the traditional extensive development model has also taken a huge toll on us (Wang et al., 2020; Gao et al.,2020). Referring to the BP World Energy Statistics Yearbook (2018), China's total energy consumption in 2017 was 4.49 billion tons of standard coal, with a 3.1\% growth in energy consumption. Meanwhile, the 2018 Global Environmental Performance Index data demonstrates that among 180 countries and regions participating in the survey, China's overall environmental performance score was 50.74, the 120th lowest worldwide. In the face of the growing imbalance between energy supply and demand, the Chinese government has incorporated energy conservation into its long-term strategic planning. In the Eleventh, Twelfth and Thirteenth Five-Year Plans, targets were set to decrease energy consumption per unit of GDP by $20 \%, 17 \%$ and $15 \%$ (Yang et al., 2020). Under the dual pressure of economic growth and energy conservation and emission reduction, enhancing energy efficiency (EE) is a must for China to realize sustainability (Sun et al., 2019). Since environmental issues have been a vital dilemma limiting the transition to a low-carbon economy in China, we focus on green total factor energy efficiency (GTFEE), and incorporate environmental regulation (ER) and technological innovation (TI) into a unified research framework.

To enhance energy use efficiency and realize high-quality growth of China's economy, TI and ER have become important enablers. TI could decrease energy consumption and pollutant emissions per unit of output, which is helpful to sustainable economy and environmental protection (Hashmi \& Alam, 2019). ER has proved favorable in enhancing EE and eliminating the externalities of pollution (Bi et al., 2014; Sun et al., 2019). The Chinese government has introduced innovative deployment models at the institutional level, focusing on reforming the present environmental governance system, fulfilling local government environmental responsibilities, and protecting the health of the population and sustainable social development. In response to environmental issues at 
various developing periods, China has proposed a flexible ER system tailored local conditions in China (Tong et al., 2020). In essence, ER is closely linked to TI, which is a crucial determinants for EE.

So, is the relationship between TI and EE linear or non-linear? What are the mechanisms and pathways through which TI contributes to energy efficiency? A study of these questions are helpful to learn the current effect of TI on energy efficiency and its underlying mechanisms, so that TI can play a vital role in green development. At present, China's environmental governance model is shifting from end-of-pipe governance to comprehensive governance with preventive governance at source (Wu et al., 2019). Therefore, is the present government ER efficient? How does ER contribute to the impact of TI on energy efficiency? This study addresses these questions, which are immediately related to the policy effectiveness, assessment and development of ER in China. It is of great practical importance.

The possible innovation points are as follows: Firstly, ER, TI and GTFEE are included in a unified framework, and the findings contribute to the mechanisms underlying the ER on EE and emission reduction. Second, for the first time, a plausible non-linear relationship between TI and GTFEE is proposed, and ER is included in the non-linear panel threshold model of TI on GTFEE. Third, the static threshold model neglects the endogeneity, leading to biases in the estimation results (Celil \& Ömer, 2016), which is tested in this study using a dynamic threshold model considering the lagged term of GTFEE. Fourth, we investigate the direct effect of TI on GTFEE, and the indirect mechanism of the impact of TI on GTFEE through interaction effects as well. Fifth, the spatial and temporal features of TI on GTFEE are analyzed under different ER.

The following study is structured as follows: Section II is a review of the relevant literature; Section III briefly provides the background and research hypothesis of energy saving and emission reducing in China; Section IV introduces the research design, constructing models and providing data description; Part V is the results of the empirical analysis; and Part VI concludes.

\section{Literature review}

Extant literature has examined issues such as the EE measurement and its influencing factors, the relationship between ER and EE, the relationship between TI and EE, and the relationship between ER and TI. There are abundant indicators for measuring EE, and the major indicators that are expansively used are single-factor and total factor energy efficiency(TFEE). The single-factor EE indicators primarily reflect the relationship between energy consumption and effective economic output. The most widely employed single factor index is energy consumption intensity, usually defined as energy consumption per unit of GDP. A number of studies in the literature that introduce energy consumption per unit of GDP as a proxy for EE have found that TI, R\&D expenditure, ownership reform and industrial structure would significantly impact EE (Kofi, 2019; Wei et al., 2007; Crompton \& Wu, 2005). TFEE is regarded as a more efficient measure of EE than single factor $\mathrm{EE}$, and $\mathrm{Hu}$ and Wang (2006) pioneered data envelopment analysis (DEA) to measure the TFEE. However, the TFEE index they adopted only included the expected output of energy use. Watanabe and Tanaka (2007) pointed out that to analyze EE, the pollution emissions associated with energy use cannot be ignored. The unexpected output measured by pollution emissions is also a kind of social cost, which will dramatically counteract the favorable impact of expected output. Later, some literatures improved the previous evaluation methods, which included the effect of unexpected output factors, and used super SBM model to calculate green TFEE(GTFEE) (Wang \& Feng, 2015; Dan et al., 2019).

Recently, conclusions of studies on the relationship between ER and EE have been inconsistent. Some scholars have argued that environmental regulations increase firms' production costs, reduce their competitiveness and negatively affect EE. For example, Ramiah et al. (2013) investigated the 
impact on stock returns and discovered that nearly all of the oil and electricity industries showed pronounced adverse abnormal returns when the Australian government announced the implementation of 'carbon reduction' environmental regulations. Hancevic \& Ignacio (2016) analyzed the impact of the 1990 amendments to the Clean Air Act on productivity and EE in Mexico and thought that the negative effect of ER on EE came from the changed productivity. However, some scholars argue that appropriate ER can incentives TI, and partly or entirely counteracts cost effects, reducing production costs and increasing productivity as well (Porter \& Linde, 1995). For example, Bi et al. (2014) conducted a study on ER and its influences on EE, demonstrating that EE in the thermal power sector has improved thanks to ER. Curtis and Lee(2019) examined micro-data at the factory stage in the annual survey of manufacturers, and found that ER could directly stimulate investment related to improving EE, which not only improved EE, but also reduced emissions.

Among the studies on the relationship between TI and EE, Garbaccfio et al. (1999) decomposed the factors influencing EE with the input-output approach, both in terms of technology and structural change, and demonstrated that TI was a significant factor in enhancing EE. Popp(2002) found that the extent to which TI improves energy efficiency is influenced by energy prices. FisherVanden et al (2006), using annual data on the industrial sector in China, found that TI and industrial restructuring were the major reasons for the descend in energy intensity. A et al. (2018) examined output elasticity, factor substitution and technological bias in three Chinese urban agglomerations and concluded that TI, while beneficial for improving energy efficiency, does not decrease emissions. Wang et al. (2019) argued that TI had heterogeneity in carbon emissions across sectors, and that while TI can increase EE in the industrial sector, it can also contribute to a growth in carbon emission. However, there is few studies examining the non-linear relationship between TI and energy efficiency.

There has been a heated debate about the impact of ER on TI, and there are currently three main views. One is that ER encourages firms to modify their emission management strategies, forcing them to look for optimal technological adaptation and further improving the efficiency and level of TI (Testa et al., 2011; Porter \& Linde, 1995). Second, to avoid penalties from strict ER, firms will restrict their production scale and raise their investment in pollutant management, which lead them to decrease their R\&D investment and discourages technological importation and cooperation (Lanoie et al., 2008; Li et al., 2019). Third, the effect of ER on TI is non-linear (Pan et al., 2019). When ER is weak, firms prefer lower-cost pollution penalties to technological change. However, as ER is strengthened, firms must enhance technological transformation so that they can avoid pollution penalties and also improve productivity and EE to cover the cost of technological transition. It can be inferred from this that the different levels of ER are likely to influence the role of TI on energy efficiency. Thus, it is important to use ER as a threshold to explore in depth the effect of TI on EE.

In summary, although scholars have widely studied EE, the existing literature is mostly about isolated studies on how ER or TI affects EE, and there is almost no literature examining the various effects of TI on EE under different levels of ER. Secondly, there is little literature on the non-linear relationship between TI and EE, and the traditional static panel threshold model ignores the lagged effects of the explanatory variables, leading to estimating errors. Finally, there are relatively few researches on the affecting pathways of $\mathrm{TI}$ on $\mathrm{EE}$, and the mechanisms of its direct or indirect effect have not been completely elucidated and verified. In view of this, this study takes GTFEE as a measure of energy efficiency, places it, TI and ER in the same research framework. And constructing dataset from 271 prefecture-level cities in China from 2004-2016, a dynamic panel threshold model is adopted to examine how ER acts on a non-linear effect between TI and GTFEE. We also attempt to verify the mechanism of the impact of TI on GTFEE through an interaction effect test, so as to disclose the mechanisms of the effects both theoretically and empirically. These 
studies provide an important basis for the formulation of targeted economic and energy policies in China's green and sustainable development stage.

\section{Background and research hypothesis}

\subsection{Background}

In the past few years, China has announced a series of policies to promote green development and energy conservation1. Simultaneously, China's investment in environmental governance rose from RMB 449 billion in 2008 to RMB 953.9 billion in 2017. These investments were aimed at improving the ecological environment and energy efficiency, but rarely successed. As a result, the Chinese government is vibrantly looking for measures to enhance EE. Studies have shown that technical innovations covering pollution control, ecological processes, and recycling are significant in promoting sustainable economic development (Ernest et al., 1994), and that pursuing TI is an effective means of breaking through current resource and environmental problems and promoting green economic development under the new normal. However, the positive knowledge externality and negative environmental externality of TI prevent enterprises from obtaining sufficient innovation benefits. Therefore, under the premise of market mechanism, effective government incentive is an effective means to compensate for the "double externality" of TI and promote enterprises to carry out TI.

With a panel dataset in China, this study introduces the Malmquist-Luenberger index method under the Super-SBM model to estimate the GTFEE of Chinese prefecture-level cities for the sample period. To visualize the regional differences and dynamics of GTFEE in China, it is displayed in a topographic map in Figure 1. Considering space restriction, results for 2004 and 2016 are presented in this study. As showed in Figure 1, among the 271 available prefecture-level city data in China, white represents cities excluded from the sample, the darker the color of the other marked cities, the higher the GTFEE, with the red areas presenting the highest level of GTFEE. From 2004 to 2016, the number of red areas gradually increased, indicating an upward trend in China's overall GTFEE. This is because during the Eleventh and Twelfth Five-Year Plans, the government made pollutant emissions a binding assessment indicator, strengthening the government's environmental responsibility. After a long-term change in economic development philosophy and the enforcement of different environmental protection policies, emissions have been efficiently decreased and the effectiveness of environmental management has been improved.
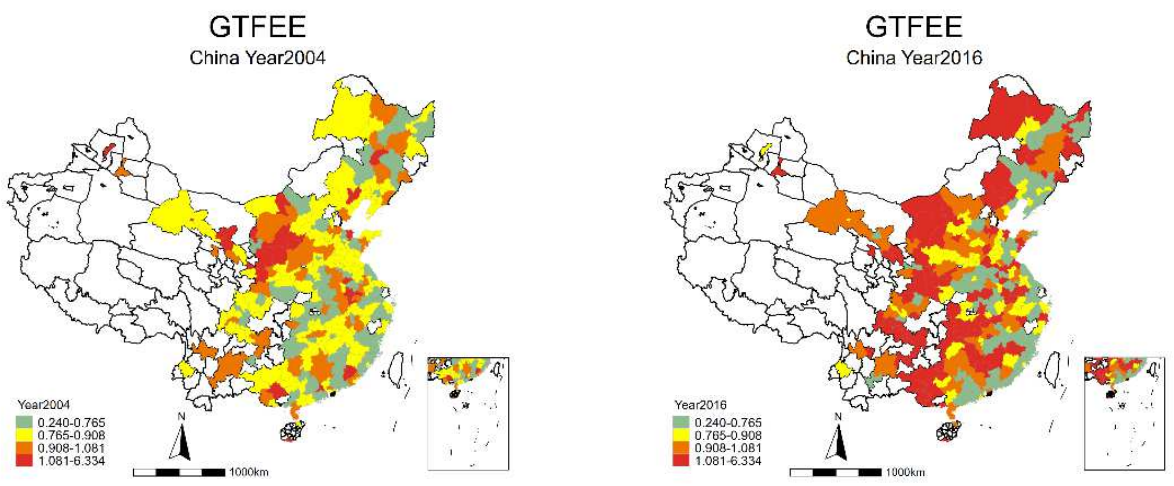

${ }^{1}$ These Chinese policies includes the Strategic Action Plan for Energy Development (2014-2020), the Law of the People's Republic of China on the Prevention and Control of Air Pollution and the Law of the People's Republic of China on Environmental Protection, collected by the authors. 


\section{2}

\subsection{Research Hypothesis}

As the impact of TI on GTFEE varies across channels under different ER intensities, it is not ideal to improve energy use efficiency and achieve improved environmental quality by increasing the intensity of local TI or ER alone. When enacting environmental policies and considering management paths, governments should fully consider the dual role of local ER and TI and implement integrated policies that combine the two. The mechanisms of the threshold effect are witnessed in Figure 2. It is clear that TI directly affects GTFEE via green TI spillover effect. Moreover, TI will also indirectly affect GTFEE via economic growth effect, industrial upgrading effect and foreign direct investment effect. Nevertheless, once the intensity of ER varies, these channels of influence would also change, ultimately leading to different impacts on GTFEE. Namely, the impact of TI on green EE is different under different ER. In this study, based on the study of the non-linear impact of TI on green EE with a dynamic panel threshold model, the direct and indirect paths of TI on GTFEE under various ER intensities are tested by introducing TI and its interaction term with channel variables. Regarding this, we formulate the following research hypothesis.

Hypothesis 1: TI is the primary measure for China to achieve economic growth while improving environmental quality, and it tends to improve energy use efficiency and clean production. TI can directly modify the traditional technologies in the production process and apply new energy-saving technologies to enhance EE ( $\mathrm{Li}$ et al., 2019b). Namely, the green technology innovation effect channel is positive.

Hypothesis 2: TI will contribute to the economic development, but in the early period, the rough development model will certainly lead to energy inefficiency. As economic growth makes the investment in scientific research increasing, different regional development strategies are gradually shifting from economic growth-centered to green and clean development, thus indirectly improving energy efficiency in the production process. Namely, the economic growth mechanism is present and uncertain.

Hypothesis 3: TI accelerates the flow of resources to the tertiary industry (Tian et al., 2019), thus the proportion of tertiary industrial output growing. As the overall industrial structure changes from the energy-intensive and resource-intensive secondary industry to the low-energy-intensive and knowledge-intensive tertiary industry, the overall economy develops in an environmentally friendly way, and improving energy use efficiency becomes a top priority. Namely, the industrial upgrading effect channels is positive.

Hypothesis 4: TI is helpful to attracting FDI. On the one hand, FDI may produce a "pollution halo" effect, where the advanced management experience and environmental technology brought by the investment will improve the environmental quality for developing countries. On the other hand, FDI may also produce a "pollution paradise" effect, which will export a large number of polluting industries, while developing countries will lower their ER standards in order to attract foreign investment, thus deteriorating the environment. That is, the channel of foreign direct investment effect exists and is uncertain. 


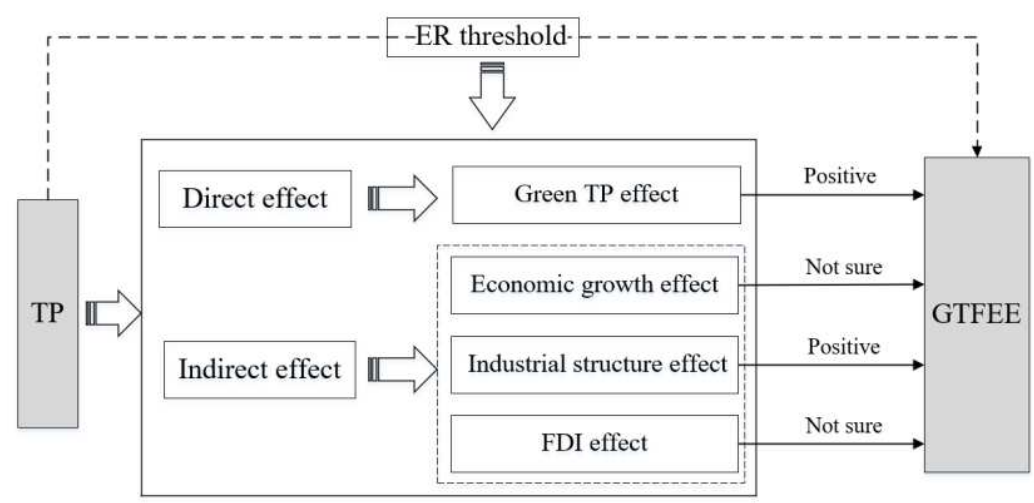

Fig 2. The transition mechanisms of the threshold effect of TP on GTFEE

\section{Methods and Data}

\subsection{Methods}

To test whether there is a dynamic non-linear relationship between TI and GTFEE under different ER intensities, we employ the dynamic panel threshold model proposed by Kremer et al. (2013) with GTFEE as the dependent variable and ER as the threshold variable. The model introduces the lagged terms of the explanatory variables into the static threshold model proposed by Hansen (2000) for estimation and is able to avoid estimation errors due to endogeneity (Wu et al., 2019). We consider the following model:

$$
\text { GFTEE }_{i t}=\alpha+\beta_{0} \text { GFTEE }_{i t-1}+\beta_{1} T I_{i t} \cdot I\left(E R_{i t}<\gamma\right)+\beta_{2} T I_{i t} \cdot I\left(E R_{i t} \geq \gamma\right)
$$

$$
+\sum_{4}^{k=1} \delta_{k} Z_{i t}+u_{i}+v_{t}+\varepsilon_{i t}
$$

In model (1), GFTEE $E_{i t}$ denotes the green total factor energy efficiency of city i in year $\mathrm{t}, T I_{i t}$ denotes the level of technical innovation of city $\mathrm{i}$ in year $\mathrm{t}, E R_{i t}$ denotes the level of environmental regulation of city $i$ in year $t, Z_{i t}$ signifies other control variables affecting GTFEE, $\beta_{1}, \beta_{2}$ denote the impact coefficients of technological innovation on GTFEE under different intensity of ERs respectively. I denotes the indicative function, $\gamma$ denotes the threshold of ER, $u_{i}$ and $\mathrm{v}_{t}$ represent the individual and time effects respectively, and $\varepsilon_{i t}$ represents the random disturbance term.

Furthermore, to assess the direct and indirect effects, we introduce the interaction terms of TI and economic growth level (PGDP), industrial structure level (STR) and foreign direct investment level (FDI), and establishes the following model, where other variables are the same as above.

$$
\begin{aligned}
\text { GFTEE }_{i t} & =\alpha+\delta_{0} \text { GFTEE }_{i t-1}+\delta_{1} T I_{i t}+\rho_{1} T I_{i t} * \mathrm{PGDP}+\rho_{2} T I_{i t} * \mathrm{STR} \\
& +\rho_{3} T I_{i t} * \mathrm{FDI}+u_{i}+v_{t}+\varepsilon_{i t}
\end{aligned}
$$

\subsection{Data}

Energy efficiency (GTFEE). How to measure energy efficiency is a controversial and ongoing research issue in academia. Patterson (1996) proposed energy consumption per unit of GDP as a proxy for EE, and Hu and Wang (2006) pioneered DEA to calculate GTFEE. Tone (2004) introduced the relaxation variables straightly into the objective function and proposed a measurement model (SMB) based on non-radial and non-angular values. Hong and Shi (2014) proposed an improved Super-SBM model based on an SBM model with non-consensual outputs and weak disposability assumptions. Drawing on sustainable development ideas and previous research findings (Hong \& Shi, 2014; Li \& Lin, 2017), this study calculates an energy efficiency index that fully considers undesired outputs, named GTFEE. Concretely, this study selected panel 
data from 271 prefecture-level cities from 2004-2016 to measure the GTFEE of each city with the Malmquist-Luenberger index design based on the Super-SBM model. The model contains inputs, desired outputs and undesired outputs. The inputs include three variables: capital stock (K), labor (L) and energy consumption (E), the desired output is selected as the gross regional product (GDP) variable, and the undesired output variables are selected as industrial sulfur dioxide (SO2), industrial soot (smoke) and industrial wastewater (effluents) emissions.

Technological innovation (TI). Intuitively, common indicators for TI consist of R\&D investment, total factor productivity and number of patents (Cheng et al., 2017; Alam \& Murad, 2020; Fei \& Lin, 2017). Regardless of the industry, TI is closely related to patent applications, and thus the number of patents is intensively employed to measure TI ( $\mathrm{Du} \& \mathrm{Li}, 2019$ ). Regarding this, we use the total number of patents granted to represent the R\&D innovation capacity of cities.

Environmental regulation (ER). The choice of ER strategy primarily influenced by the willingness of local governments to govern the environment, and the intensity of ER varies from region to region. Based on such typical characteristics, it is relatively more objective to reflect the intensity of ER from the results of pollution control. This study extends the measurement of ER at the provincial level by $\mathrm{Wu}$ et al. (2020) to the city level. In view of data availability and completeness, a composite index of ER was constructed based on the two individual indexes of industrial fume and dust removal rate and Centralized treatment rate of sewage treatment plants. The precise method is as follows:

First, the two indicators, industrial fume and dust removal rate and centralized treatment rate of sewage treatment plants, are standardized according to Equation (3), where $p t_{i j}$ denotes the original value of the indicator of category $\mathrm{j}$ in city $\mathrm{i}$, and $\min \left(p t_{j}\right)$ and $\max \left(p t_{j}\right)$ denote the minimum and maximum values of the indicator of category $\mathrm{j}$ in all cities, respectively.

$$
p t_{i j}^{s}=\left[p t_{i j}-\min \left(p t_{j}\right)\right] /\left[\max \left(p t_{j}\right)-\min \left(p t_{j}\right)\right]
$$

Then, the adjustment coefficients $A_{i j}$ for the two indicators are calculated separately for different cities, indicating the ratio of the share of pollutant $j$ emitted by city $i$ in the country to the share of GDP of city $\mathrm{i}$ in the country, and the calculation formula is as in Equation (4). The calculation of $A_{i j}$ shows that if a city has higher emissions of a certain pollutant, then the same pollutant treatment rate implies higher ER and therefore gives a greater weight.

$$
A_{i j}=\frac{p_{i j}}{\sum_{i} p_{i j}} / \frac{g d p_{i}}{\sum_{i} g d p_{i}}
$$

Finally, from the standardized values and adjustment coefficients of the industrial fume and dust removal rate and the centralized treatment rate of the wastewater treatment plant, the degree of ER for city $i$ is obtained, calculated as in Equation (5).

$$
E R_{i}=\sum_{2}^{j=1} A_{i j} p t_{i j}^{s} / 2
$$

Control variables. To alleviate the problem of bias in the regression results due to omitted variables in the model, urban characteristics-related variables were controlled for in model (1) with reference to the studies by Liu et al., (2020). Gross regional product per capita (PGDP), obtained by dividing the city's GDP by the total year-end population of the city, which measures the degree of economic growth. Industrial structure (STR), defined as the share of GDP accounted for by the gross secondary industry. Foreign direct investment (FDI), expressed as the amount of FDI converted from the US dollar to the RMB exchange rate. The specific meaning of each variable and the measurement criteria are represented in Table 1.

Tab 1 Selection and connotation of variables 


\begin{tabular}{|c|c|c|}
\hline Variable name & Symbol & connotation \\
\hline Green Total Factor Energy Efficiency & GTFEE & BM-Malmquist-Luenberger index method \\
\hline Technological innovation & $\mathrm{TI}$ & Total number of patents granted \\
\hline Environmental Regulation & ER & Comprehensive exponential method \\
\hline Industrial structure & STR & $\begin{array}{l}\text { The proportion of Tertiary sector output in } \\
\text { GDP }\end{array}$ \\
\hline Foreign direct investment & FDI & The proportion of FDI in GDP \\
\hline Gross regional product per capita & PGDP & Real GDP per capita \\
\hline
\end{tabular}

336

337

338

339

340

341

342

343

344

345

The data in this study cover 271 Chinese prefecture-level city-level data from 2004-2016, and data on per capita gross regional product are price-deflated with 2003 as the base year. energy consumption data are accessible in the China Energy Statistical Yearbook, other variables are derived from the China Environmental Statistical Yearbook, China Environmental Yearbook, China Energy Statistical Yearbook, China Science and Technology Statistical Yearbook, and the National Bureau of Statistics. Table 2 provides the descriptive statistics.

Table 2 Descriptive statistical analysis of variables.

\begin{tabular}{lrrrrr}
\hline Variable & Obs & Mean & Std. Dev. & Min & Max \\
\hline $\ln$ GTFEE & 3523 & -0.096 & 0.339 & -1.425 & 1.846 \\
$\operatorname{lnEI}$ & 3523 & 0.198 & 0.824 & -1.798 & 4.137 \\
TI & 3523 & 6.166 & 1.769 & 0.693 & 11.419 \\
STR & 3523 & 0.494 & 0.108 & 0.090 & 0.910 \\
FDI & 3523 & 0.253 & 0.217 & 0.000 & 0.676 \\
InPGDP & 3523 & 8.477 & 0.688 & 6.330 & 10.673 \\
ER & 3523 & 1.123 & 1.695 & 0.001 & 60.012 \\
\hline
\end{tabular}

\section{Analysis of Empirical Results}

\subsection{Estimation of dynamic panel threshold model}

We investigate how TI affect GTFEE with a dynamic panel threshold model with ER as the threshold variable, based on the introduction of a one-period lag of GTFEE, and Table 3 provide the results. Model (1) excludes control variables, where the threshold value of ER is 0.3355 . The coefficient of the impact of TI on GTFEE is 0.053 and significant at the $1 \%$ level when the intensity of ER is above its threshold, and 0.051 when it is below its threshold, which is significant at the 5\% level. Models (2)-(4) represent the regression results with the step-by-step addition of other controls, and the threshold for ER remains at 0.3355, indicating that the effect of TI on GTFEE is non-linear and that their relationship changes with the corresponding magnitude of ER. At the same time, we observe that although the coefficient value of the threshold effect $\beta_{1}, \beta_{2}$ changes, it is still significant and positive, and $\beta_{2}$ is always greater than $\beta_{1}$. This suggests that a dynamic threshold effect of TI on GTFEE does exist, and the consistency of the regression results across the four models supports the robustness of the findings.

The economic reasons behind the non-linear effect may lie in the fact that when a region is at the poverty stage, economic growth is the main development objective and the level of ER is lower. During this period, TI tends to increase output, and although it witnesses a favorable influence on $\mathrm{EE}$, it is relatively ineffective. When a region reaches a certain stage of economic growth and begins to focus on green and sustainable development, the level of ER will increase. At this period, TI is more inclined to green, which can help economic growth, an improve environment and EE. Therefore, TI has a greater role in improving GTFEE when ER crosses the threshold. China's current 
strict ER has indeed improved China's overall EE, but environmental control is a long-term course that cannot depend merely on policies and should focus on the linkage between TI and ER. Meanwhile, the lagged terms of GTFEE are all pronounced(1\% level) under different control variables, indicating that GTFEE has a certain path dependence, and past energy efficiency affects current energy efficiency.

Table 3 Dynamic threshold effect and robustness test of TI on GTFEE

\begin{tabular}{|c|c|c|c|c|}
\hline & Model 1 & Model 2 & Model 3 & Model 4 \\
\hline \multicolumn{5}{|c|}{ A1:Estimation of threshold value } \\
\hline r & 0.3355 & 0.3355 & 0.3355 & 0.3355 \\
\hline \multicolumn{5}{|c|}{ B1:Influence of TI on lngtfpe } \\
\hline \multirow[t]{2}{*}{$\beta_{1}$} & $0.051 * *$ & $0.037 * *$ & $0.044 * *$ & $0.037 *$ \\
\hline & $(0.03)$ & $(0.02)$ & $(0.02)$ & $(0.02)$ \\
\hline \multirow[t]{2}{*}{$\beta_{2}$} & $0.053 * * *$ & $0.047 * * *$ & $0.051 * * *$ & $0.039 * *$ \\
\hline & $(0.01)$ & $(0.01)$ & $(0.01)$ & $(0.02)$ \\
\hline \multicolumn{5}{|c|}{$\mathrm{C} 1$ :Influence of the hysteresis of lngtfpe on lngtfpe } \\
\hline \multirow[t]{2}{*}{ L.lngtfpe } & $0.451 * * *$ & $0.707 * * *$ & $0.745 * * *$ & $0.714 * * *$ \\
\hline & $(0.14)$ & $(0.07)$ & $(0.07)$ & $(0.05)$ \\
\hline \multicolumn{5}{|c|}{ D1:Influence of control variables on lngtfpe } \\
\hline \multirow[t]{2}{*}{ STR } & & 0.370 & $0.779 * * *$ & 0.549 \\
\hline & & $(0.30)$ & $(0.30)$ & $(0.35)$ \\
\hline \multirow[t]{2}{*}{ FDI } & & & $-0.304 * * *$ & $-0.351 * * *$ \\
\hline & & & $(0.10)$ & $(0.09)$ \\
\hline \multirow[t]{2}{*}{ GDP } & & & & 0.036 \\
\hline & & & & $(0.04)$ \\
\hline \multirow[t]{2}{*}{ _cons } & $-0.350 * * *$ & $-0.484 * * *$ & $-0.618 * * *$ & $-0.732 * * *$ \\
\hline & $(0.06)$ & $(0.13)$ & $(0.12)$ & $(0.22)$ \\
\hline $\mathrm{N}$ & 3252 & 3252 & 3252 & 3252 \\
\hline $\mathrm{N}_{\text {_ individual }}$ & 271 & 271 & 271 & 271 \\
\hline Individual FE & YES & YES & YES & YES \\
\hline Time FE & YES & YES & YES & YES \\
\hline Wald test & 297.12 & 1066.9 & 1073.1 & 1169.8 \\
\hline
\end{tabular}

375

376

denoted in parentheses.

\subsection{Test of impact channels}

To estimate equation (2), OLS, differential GMM and systematic GMM estimators are extensively employed, while only the third method is helpful to eliminate endogeneity and avoid weak instrumental variable (Blundell \& Bond, 1998). Thus, we adopt the systematic GMM design to estimate equation (2). Simultaneously, based on the previous analysis, we explore the impact of TI on GTFEE in the full sample, the low ER level sample (the sample with ER level below the threshold), and the high ER level sample (the sample with ER level above the threshold) respectively, and Table 4 reports the results.

Firstly, the coefficient on TI is significantly positive in all three estimations, indicating that TI has a favorable direct impact on GTFEE for the full sample, the low ER level sample and the high ER level sample. Thus, Hypothesis 1 is further confirmed. Moreover, we also find that the direct effect is stronger in the high ER level sample than in the low ER level, suggesting that TI at high ER levels is more conducive to energy efficiency. First of all, high ER levels force firms to introduce 
clean production technology and allocate more capital in green R\&D (Pan et al., 2019); furthermore, firms' green TI will enhance EE of both themselves and other firms via knowledge spillover effects, resulting in the decline of energy consumption of the entire areas. Thus, TI inspired by stronger ER is more favorable to enhancing GTFEE (Barbieri, 2015).

Secondly, from the full sample, the economic growth effect, the industrial structure effect and the foreign direct investment effect are all significant, in other words, the indirect influence mechanisms are effective. The coefficient of the cross-sectional term between TI and GDP per capita is significantly negative at the $1 \%$ level, which confirms hypothesis 2 and verifies that China's overall economic growth is still in a rough development mode. For the economic growth effect of TI, first of all, it needs to consume a large amount of energy resources and the rough development model may lead to low green EE; moreover, it can improve green EE by increasing R\&D investment to enhance production efficiency. The negative cross coefficient demonstrates the rough development model is still dominant in overall economy. It is clear that the coefficient of the cross term between TI and STR is significantly positive at the 5\% level, and hypothesis 3 is confirmed. For the industrial structure effect of TI, TI accelerates the flow of resources to the tertiary sector, thereby raising tertiary output share, the overall economy moves towards an environmentally friendly development, and improving energy use efficiency becomes a top priority. The coefficient of the cross-sectional term between TI and FDI is significantly positive, confirming hypothesis 4 , namely, TI can influence GTFEE through the foreign investment effect. At the early stage of foreign investment introduction, the technology absorption capacity is insufficient, coupled with low ERs there may be a "pollution paradise effect", failing to significantly improve the GTFEE. With the introduction of foreign capital, its knowledge spillover effect and demonstration effect are enhanced, which is manifested as the "pollution halo effect", the level of local TI is continuously enhanced, and the GTFEE is also greatly improved. The significant positive coefficient of the cross term in the empirical results indicates the dominance of the pollution halo effect.

Finally, different impact mechanisms are shown for the sub-sample at low and high levels of ER. The indirect impact mechanism of TI on GTFEE is not pronounced when ER is in the low ER level range, but it starts to be effective when the ER level exceeds the threshold. When ER is in the high ER level range, TI will improve GTFEE via economic growth effect, industrial structure upgrading effect and foreign direct investment effect, which confirms hypotheses 2, 3 and 4 . This heterogeneity is primarily due to the fact that when the level of ER is low, it is unable to encourage the optimal industrial upgrading from an green development direction, making it hard to use resources intensively(Brunel \& Johnson, 2019; Zhou et al., 2017). When the level of ER increases, TI shows a clear preference for green technology and can improve GTFEE through industrial upgrading and foreign direct investment effects. Therefore, the channels through which TI affects GTFEE vary under different levels of ER.

Table 4 Channel analysis of TP affecting GTFEE

\begin{tabular}{llll}
\hline \multirow{2}{*}{ Variables } & $\begin{array}{l}\text { Model 5 } \\
\text { all sample }\end{array}$ & $\begin{array}{l}\text { Model 6 } \\
\text { low_ER }\end{array}$ & $\begin{array}{l}\text { Model 7 } \\
\text { High_ER }\end{array}$ \\
\hline TI & $0.067^{* * *}$ & $0.79^{*}$ & $0.112^{* * *}$ \\
& $(0.02)$ & $(1.09)$ & $(0.02)$
\end{tabular}




$\begin{array}{llll}\text { TI×PGDP } & -0.011^{* * *} & 0.054 & -0.030^{* * * *} \\ \text { TI×STR } & (0.00) & (0.15) & (0.01) \\ & 0.019^{* *} & -0.234 & 0.082^{* * *} \\ \text { TI×FDI } & (0.02) & (0.57) & (0.03) \\ & 0.049^{* * *} & -0.061 & 0.054 * * * \\ \text { _cons } & (0.01) & (0.13) & (0.01) \\ & 0.729 & -1.018^{* * * *} & -0.688^{* * * *} \\ \text { N } & (5.28) & (0.16) & (0.11) \\ \text { N_individual } & 3252 & 319 & 2729 \\ \text { Individual FE } & 271 & 68 & 259 \\ \text { Time FE } & \text { YES } & \text { YES } & \text { YES } \\ \text { Wald test } & \text { YES } & \text { YES } & \text { YES } \\ \text { Prob>chi2 } & 7079.49 & 936.16 & 4501.38 \\ \text { Note: ***, **, and * indicate the significance at } 1 \%, 5 \%, \text { and } 10 \% \text { levels, respectively; Standard errors are } \\ \text { enoted in parentheses. }\end{array}$

\subsection{Analysis of spatiotemporal heterogeneity}

In fact, the impact of TI on GTFEE is also spatially and temporally heterogeneous due to the threshold effect of TI on GTFEE. For example, in a given year, the level of ER varies across cities, with some cities exceeding the threshold and others falling below it, resulting in spatial heterogeneity as the effect of TI on GTFEE is greater among areas that cross the threshold than among areas that do not. Similarly, the level of ER varies between years in the same city, with some years exceeding the threshold and others not, thus creating temporal heterogeneity. Thus, spatial and temporal heterogeneity of TI work in improving GTFEE across regions and years.

From a temporal perspective, Figure 3 reports cities with levels of ER above the threshold in each of the 271 sample cities over the sample period. It can be seen that in each year from 20042016, more than half of the cities had ER levels above the threshold, with 3,059 samples above the threshold over the last 13 years, accounting for $86.83 \%$ of the total sample size. At the same time, the intensity of ER has been increasing, from 0.949 in 2004 to 1.47 in 2016. this indicates that more and more cities are exceeding the ER threshold over time, and that China's ER has generally increased, which is conducive to TI playing a role in improving GTFEE.

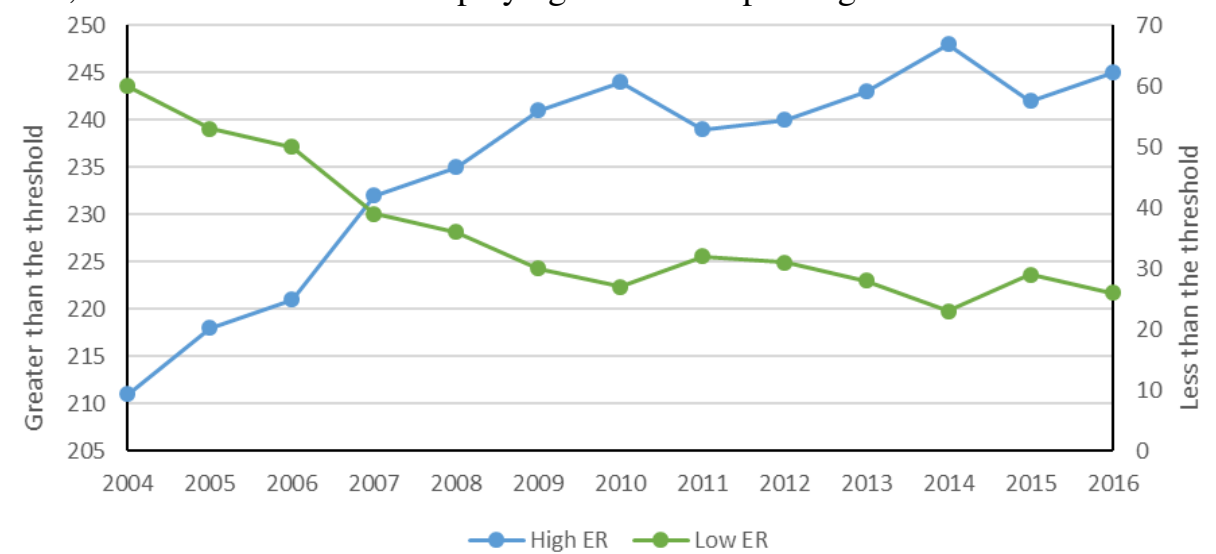

Fig 3. Number of cities with ER greater/less than the threshold.

From a spatial perspective, Figure 4 reports how many years in which the level of ER exceeded the threshold for each prefecture-level city. In the 13 years from 2004-2016, the majority of cities 
exceeded the threshold in at least half of the years, and we focus on those cities that exceeded the ER threshold in only a small number of years. Prefectural-level city data is more relevant than provincial data in suggesting appropriate environmental management policies to local governments. Nowadays, China's environmental management system contains laws and regulations made by the central and local governments, forming an supervision scheme that combines national supervision and management with division of labor supervision and management, and differences in local government supervision lead to various strength of ER from disparate areas (Xie et al., 2017). As can be seen from Figure 4, Weihai, Wenzhou and Changsha exceeded the ER threshold in only one year, Nanchong and Putian in only two years, and Taizhou, Bazhong, Kunming and Fuzhou in only three years. Therefore, the level of ER in these cities needs to be further improved, otherwise the role of TI in improving GTFEE will be limited.

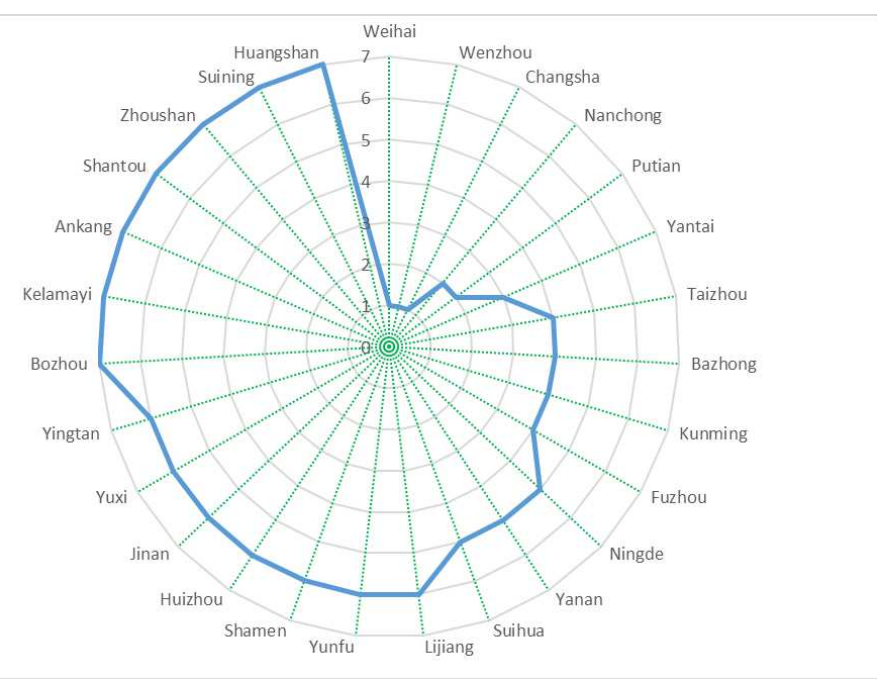

Fig 4. Numbers of years in which ER was greater than the threshold in the cities which less than 8 from 2004 to 2016.

\section{Conclusions and policy implications}

This study analyses the effect of TI on GTFEE by building a dynamic panel threshold model with a Chinese dataset. Additionally, we adopt the System GMM to verify the channel of technological innovation affecting green total factor energy efficiency. We draw the following conclusions. First of all, a non-linear dynamic threshold effect of TI on GTFEE is indeed exist. On the one hand, GTFEE has a certain path dependency, where past energy efficiency affects current energy efficiency. On the other hand, TI can significantly enhance GTFEE, and this enhancement effect differs under different levels of ER, with the enhancement effect under high levels of ER being greater than that under low levels of ER. Secondly, an examination of the channels of influence shows that when the level of ER is below its threshold, the indirect channel of influence of TI on GTFEE is not smooth, but when ER level crosses its threshold, TI can influence GTFEE through indirect channels including economic growth effect, industrial structure effect, and foreign direct investment effect. Thirdly, from the perspective of ER, the impact of TI on GTFEE is spatially and temporally heterogeneous. As time changes, more and more cities in China exceed the threshold 
of ER, which facilitates the role of TI in improving GTFEE. From a spatial perspective, there are still some cities in China with low levels of ER, which limits the role of TI in improving GTFEE.

The following policy recommendations are made in response to these findings. Firstly, we should develop TI to enhance EE industriously, encourage cooperation between industry, universities and research institutes, and support research and development by enterprises and research institutes in clean production and ecological protection. Deepen the reform of the rigid system that hinders scientific and TI, improve supporting mechanisms and optimize the environment for scientific and TI. Secondly, the intensity of ERs should be increased to stimulate enterprises to carry out green TI, so as to realize the linkage between TI and ERs. In areas with higher ERs focus on promoting TI, while in areas with lower ERs, such as cities like Weihai, Wenzhou, Nanchong, Putian, Taizhou, Bazhong, Kunming and Fuzhou, ERs should be further strengthened to focus on promoting green-biased TI. Third, gradually realize the green sustainable high-quality development mode to replace the traditional extensive development mode. Further expand the scope of R\&D and promotion of green technologies change, promote high energy consumption industries' transformation, accelerate industrial upgrading, and realize rational energy use. The introduction of foreign-funded enterprises should combine with the local ER level, focus on high-tech industry, improve the absorption capacity of advanced technology, and prevent pollution paradise effect.

Funding : This study was financed by Major Project of Philosophy and Social Science Research of China Ministry of Education under grant number 10JZD0017.The Foundation of Huazhong University of Science and Technology, under grant number HUST2109516

Author contributions : Da Gao and Yi Li conceived and designed the research question. Ge Li constructed the models and analyzed the optimal solutions. Ge Li wrote the paper. Da Gao reviewed and edited the manuscript. All authors read and approved the manuscript

Data availability : The datasets generated and/or analyzed during the current study are property of National Bureau of Statistics, they are available from the corresponding author who will inform National Bureau of Statistics that the data will be released on reasonable request.

Compliance with ethical standards

Conflict of interests The authors declare that they have no conflict of interest.

Ethics approval and consent to participate Not applicable

Consent to participate

Not applicable

Consent to publish

Not applicable 


\section{References:}

A, P. J., B, K. L. and C, S. S., 2018, "Choice of Technological Change for China's Low-Carbon Development: Evidence From Three Urban Agglomerations", Journal of Environmental Management, 206: 1308-1319.

Alam, M. M. and Murad, M. W., 2020, "The Impacts of Economic Growth, Trade Openness and Technological Progress On Renewable Energy Use in Organization for Economic Co-Operation and Development Countries", Renewable Energy, 145(Jan.): 382-390.

Barbieri, N., 2015, "Investigating the Impacts of Technological Position and European Environmental Regulation On Green Automotive Patent Activity", Ecological Economics, 117(SEP.): 140-152.

Bi, G., Song, W., Zhou, P. and Liang, L., 2014, "Does Environmental Regulation Affect Energy Efficiency in China's Thermal Power Generation? Empirical Evidence From a Slacks-Based Dea Model", Energy Policy, 66.

Blundell, R. and Bond, S., 1998, "Initial Conditions and Moment Restrictions in Dynamic Panel Data Models", Economics Papers.

Brunel, C. and Johnson, E. P., 2019, "Two Birds, One Stone? Local Pollution Regulation and Greenhouse Gas Emissions", Energy Economics, 78(FEB.): 1-12.

Celil, A. and ömer, E., 2016, "Does the Level of Energy Intensity Matter in the Effect of Energy Consumption On the Growth of Transition Economies? Evidence From Dynamic Panel Threshold Analysis", , 69.

Cheng, Z., Li, L. and Liu, J., 2017, "Industrial Structure, Technical Progress and Carbon Intensity in China's Provinces", Renewable \& Sustainable Energy Reviews, 81(pt.2): 2935-2946.

Crompton, P. and Wu, Y., 2005, "Energy Consumption in China: Past Trends and Future Directions", Energy Economics, 27(1): 195-208.

Curtis, E. M. and Lee, J. M., 2019, "When Do Environmental Regulations Backfire? Onsite Industrial Electricity Generation, Energy Efficiency and Policy Instruments", Journal of Environmental Economics \& Management, 96.

Dan, Y. A. B., Ying, K. A. C., D, B. Y., E, Y. S. and F, X. Z., 2019, "Spatial Variation of Energy Efficiency Based On a Super-Slack-Based Measure: Evidence From 104 Resource-Based Cities", Journal of Cleaner Production, 240.

Du, K. and Li, J., 2019, "Towards a Green World: How Do Green Technology Innovations Affect Total-Factor Carbon Productivity", Energy Policy, 131(AUG.): 240-250.

Ernest, Braun, David and Wield, 1994, "Regulation as a Means for the Social Control of Technology", Technology Analysis \& Strategic Management.

Fei, R. and Lin, B., 2017, "The Integrated Efficiency of Inputs-Outputs and Energy - Co2 Emissions Performance of China's Agricultural Sector", Renewable \& Sustainable Energy Reviews.

Fisher-Vanden, K., Jefferson, G. H., Ma, J. and Xu, J., 2006, "Technology Development and Energy Productivity in China", Energy Economics, 28(5-6): 690-705.

Gao, D., Y. Li and Q. Yang, Can pollution charges reform promote industrial SO 2 emissions reduction?-Evidence from 189 China's cities. Energy \& Environment, 2020: p. 0958305X2091941.

Garbaccio, Richard, F., Mun, S., Jorgenson and Dale, W., 1999, "Why Has the Energy-Output Ratio Fallen in China?", Energy Journal.

Hancevic and Ignacio, P., 2016, "Environmental Regulation and Productivity: The Case of 
Hansen B. E., 2000, "Sample Splitting and Threshold Estimation", Econometrica.

Hashmi, R. and Alam, K., 2019, "Dynamic Relationship Among Environmental Regulation, Innovation, Co 2 Emissions, Population, and Economic Growth in Oecd Countries: A Panel Investigation", Journal of Cleaner Production, 231.

Hong, L. and Shi, J. F., 2014, "Energy Efficiency Analysis On Chinese Industrial Sectors: An Improved Super-Sbm Model with Undesirable Outputs", Journal of Cleaner Production, 65(FEB.15): 97 107.

Hu, J. L. and Wang, S. C., 2006, "Total-Factor Energy Efficiency of Regions in China", Energy Policy, 34(17): 3206-3217.

Kofi, E. B., 2019, "Institutional Quality, Green Innovation and Energy Efficiency", Energy Policy, 135: 111002 .

Kremer S., Bick A., Nautz D., 2013, "Inflation and Growth: New Evidence From a Dynamic Panel Threshold Analysis", Empirical Economics, 44(2), pp.861 878.

Lanoie, P., Patry, M. and Lajeunesse, R., 2008, "Environmental Regulation and Productivity: Testing the Porter Hypothesis", Journal of Productivity Analysis, 30(2): 121-128.

Li, J. and Lin, B., 2017, "Ecological Total-Factor Energy Efficiency of China's Heavy and Light Industries: Which Performs Better?", Renewable \& Sustainable Energy Reviews.

Li, W., Zhao, T., Wang, Y., Zheng, X. and Yang, J., 2019a, "How Does Foreign Direct Investment Influence Energy Intensity Convergence in China? Evidence From Prefecture-Level Data", Journal of Cleaner Production, 219(MAY 10): 57-65.

Li, W., Zhao, T., Wang, Y., Zheng, X. and Yang, J., 2019b, "How Does Foreign Direct Investment Influence Energy Intensity Convergence in China? Evidence From Prefecture-Level Data", Journal of Cleaner Production, 219(MAY 10): 57-65.

Liu, X., Sun, T., Feng, Q. and Zhang, D., 2020, "Dynamic Environmental Regulation Threshold Effect of Technical Progress On China'S Environmental Pollution", Journal of Cleaner Production, 272: 122780 .

Pan, X., Ai, B., Li, C., Pan, X. and Yan, Y., 2019, "Dynamic Relationship Among Environmental Regulation, Technological Innovation and Energy Efficiency Based On Large Scale Provincial Panel Data in China", Technological Forecasting \& Social Change, 144(JUL.): 428-435.

Patterson, M. G., 1996, "What is Energy Efficiency?", Energy Policy, 24(5): 377-390.

Popp, D., 2002, "Induced Innovation and Energy Prices", American Economic Review, 92(1).

Porter, M. E. and Linde, C. V. D., 1995, "Toward a New Conception of the EnvironmentCompetitiveness Relationship", Journal of Economic Perspectives, 9(4): 97-118.

Ramiah, V., Martin, B. and Moosa, I., 2013, "How Does the Stock Market React to the Announcement of Green Policies?", Journal of Banking \& Finance, 37(5): 1747-1758.

Sun, C., Ding, D., Fang, X., Zhang, H. and Li, J., 2019, "How Do Fossil Energy Prices Affect the Stock Prices of New Energy Companies? Evidence From Divisia Energy Price Index in China's Market", Energy, 169.

Sun, D., Zeng, S., Lin, H., Meng, X. and Yu, B., 2019, "Can Transportation Infrastructure Pave a Green Way? A City-Level Examination in China", Journal of Cleaner Production, 226: 669-678.

Testa, F., Iraldo, F. and Frey, M., 2011, "The Effect of Environmental Regulation On Firms' Competitive Performance: The Case of the Building \& Construction Sector in some Eu Regions", Journal of Environmental Management, 92(9): 2136-2144. 
Tian, X., Bai, F., Jia, J., Liu, Y. and Shi, F., 2019, "Realizing Low-Carbon Development in a Developing and Industrializing Region: Impacts of Industrial Structure Change On Co2 Emissions in Southwest China", Journal of Environmental Management, 233: 728-738.

Tone, K., 2004, "A Hybrid Measure of Efficiency in Dea", Grips Research Report Series.

Tong, Y., Liu, J. and Liu, S., 2020, "China is Implementing "Garbage Classification" Action", Environmental Pollution, 259.

Wang, K., Pang, S., Ding, L. and Miao, Z., 2020, "Combining the Biennial Malmquist-Luenberger Index and Panel Quantile Regression to Analyze the Green Total Factor Productivity of the Industrial Sector in China", Science of the Total Environment, 739.

Wang, S., Zeng, J. and Liu, X., 2019, "Examining the Multiple Impacts of Technological Progress On Co2 Emissions in China: A Panel Quantile Regression Approach", Renewable \& Sustainable Energy Reviews, 103: 140-150.

Wang, Z. and Feng, C., 2015, "A Performance Evaluation of the Energy, Environmental, and Economic Efficiency and Productivity in China: An Application of Global Data Envelopment Analysis", Applied Energy, 147(jun.1): 617-626.

Watanabe, M. and Tanaka, K., 2007, "Efficiency Analysis of Chinese Industry: A Directional Distance Function Approach", Energy Policy, 35(12): 6323-6331.

Wei, Y. M., Liao, H. and Fan, Y., 2007, "An Empirical Analysis of Energy Efficiency in China's Iron and Steel Sector", Energy, 32(12): 2262-2270.

Wu, G., Baležentis, T., Sun, C. and Xu, S., 2019, "Source Control Or End-of-Pipe Control: Mitigating Air Pollution at the Regional Level From the Perspective of the Total Factor Productivity Change Decomposition", Energy Policy, 129.

Wu, H., Hao, Y. and Ren, S., 2020, "How Do Environmental Regulation and Environmental Decentralization Affect Green Total Factor Energy Efficiency: Evidence From China", Energy Economics, 91: 104880.

Wu H., Hao Y., Weng J. H., 2019, "How Does Energy Consumption Affect China's Urbanization? New Evidence From Dynamic Threshold Panel Models", Energy Policy, 127(APR.), pp.24 38.

Xie, R. H., Yuan, Y. J. and Huang, J. J., 2017, "Different Types of Environmental Regulations and Heterogeneous Influence On "Green" Productivity: Evidence From China", Ecological Economics, 132(FEB.): 104-112.

Yang, Y., Xue, R. and Yang, D., 2020, "Does Market Segmentation Necessarily Discourage Energy Efficiency?", Plos One, 15(5): e233061.

Zhou, Y., Zhu, S. and He, C., 2017, "How Do Environmental Regulations Affect Industrial Dynamics? Evidence From China's Pollution-Intensive Industries", Habitat International, 60: 10-18. 


\section{Figures}

GTFEE

China Year2004

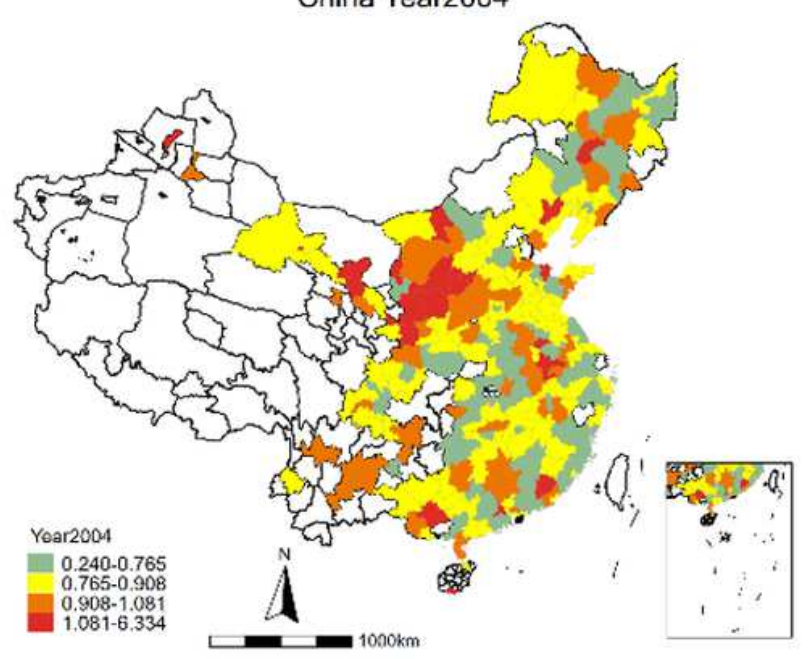

GTFEE

China Year2016

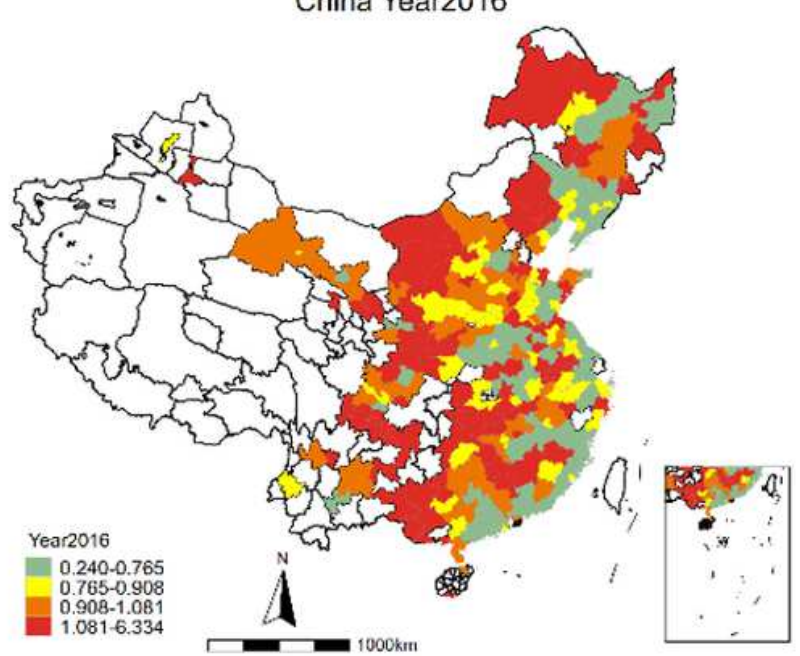

\section{Figure 1}

GTFEE of China in 2004 and 2016 Note: The designations employed and the presentation of the material on this map do not imply the expression of any opinion whatsoever on the part of Research Square concerning the legal status of any country, territory, city or area or of its authorities, or concerning the delimitation of its frontiers or boundaries. This map has been provided by the authors.

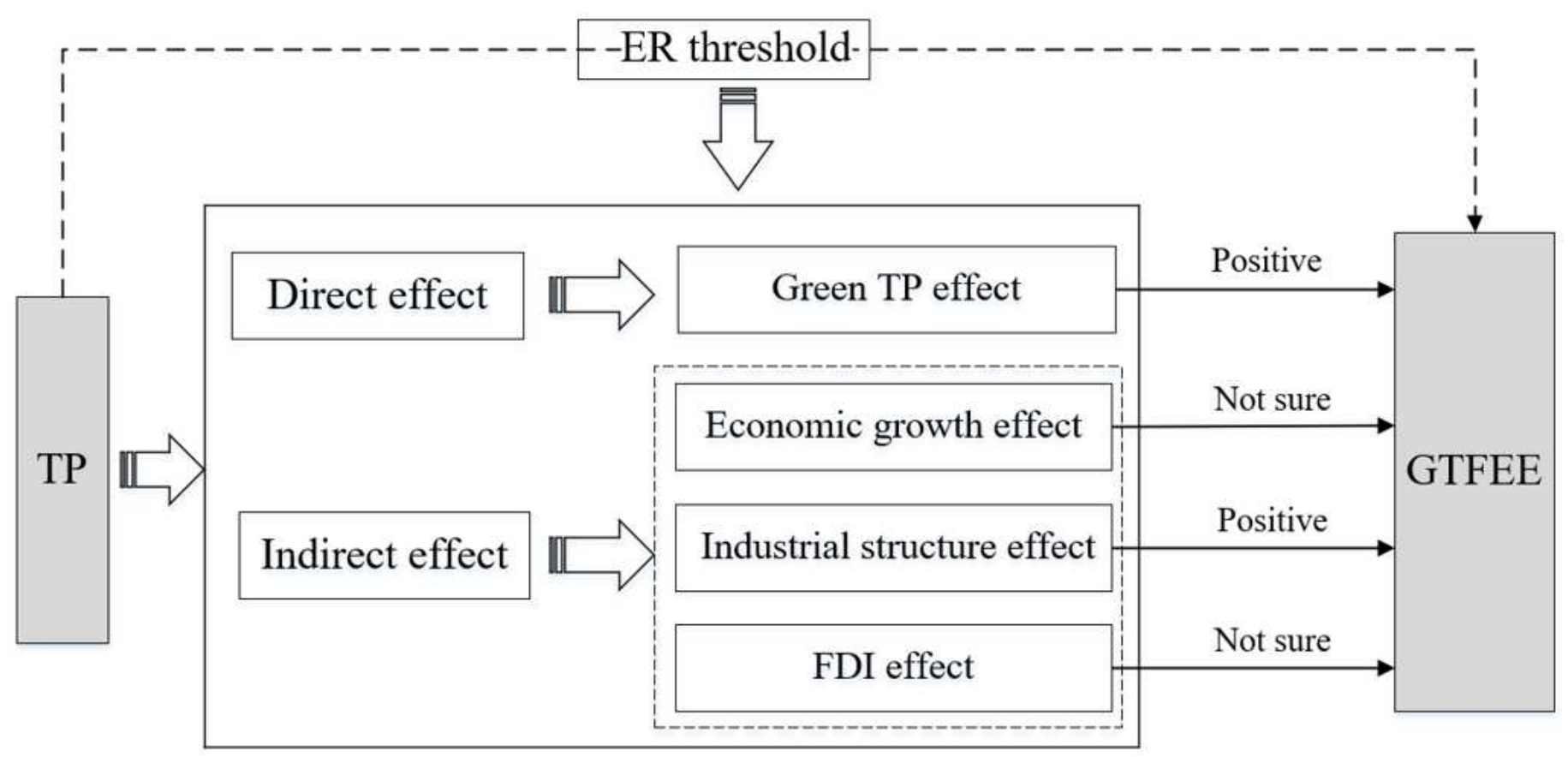

Figure 2 
The transition mechanisms of the threshold effect of TP on GTFEE

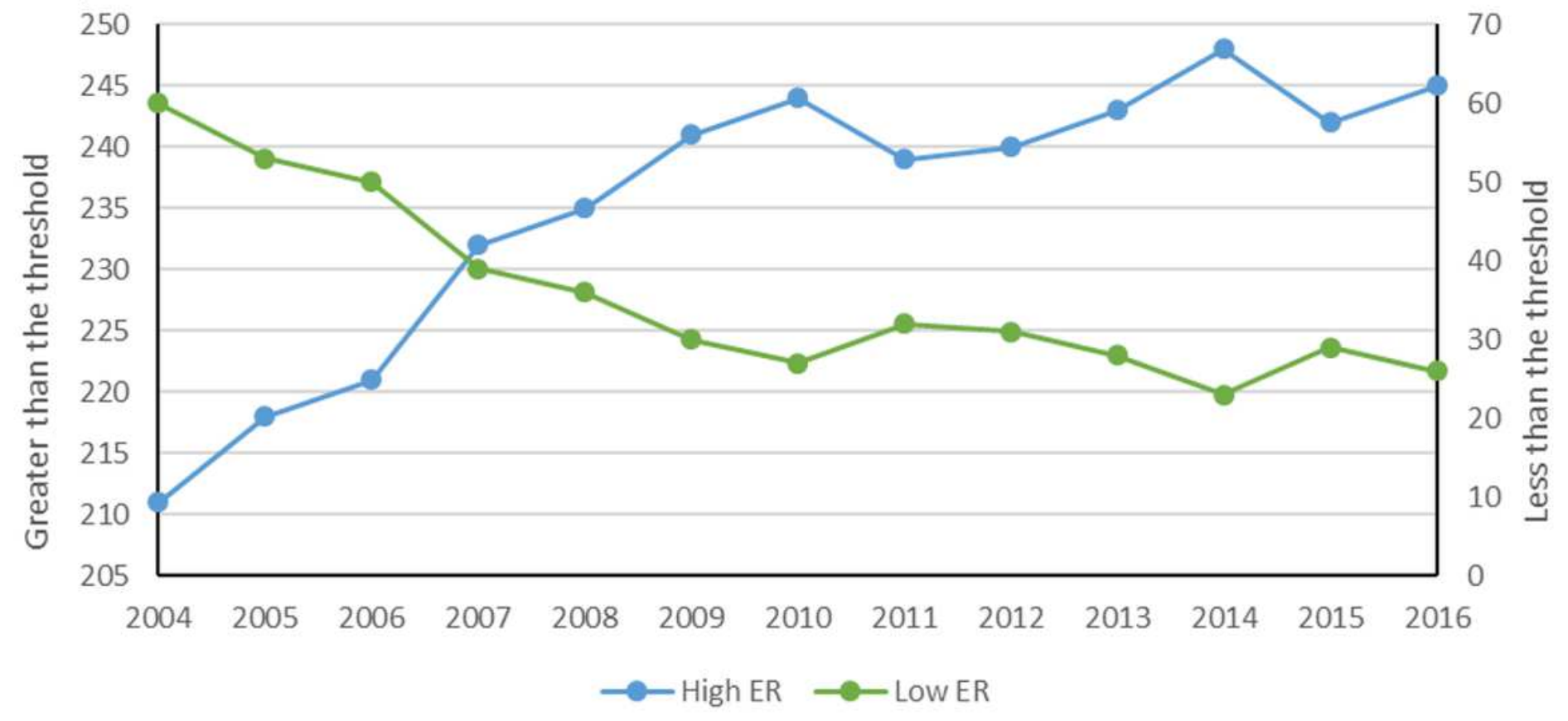

\section{Figure 3}

Number of cities with ER greater/less than the threshold.

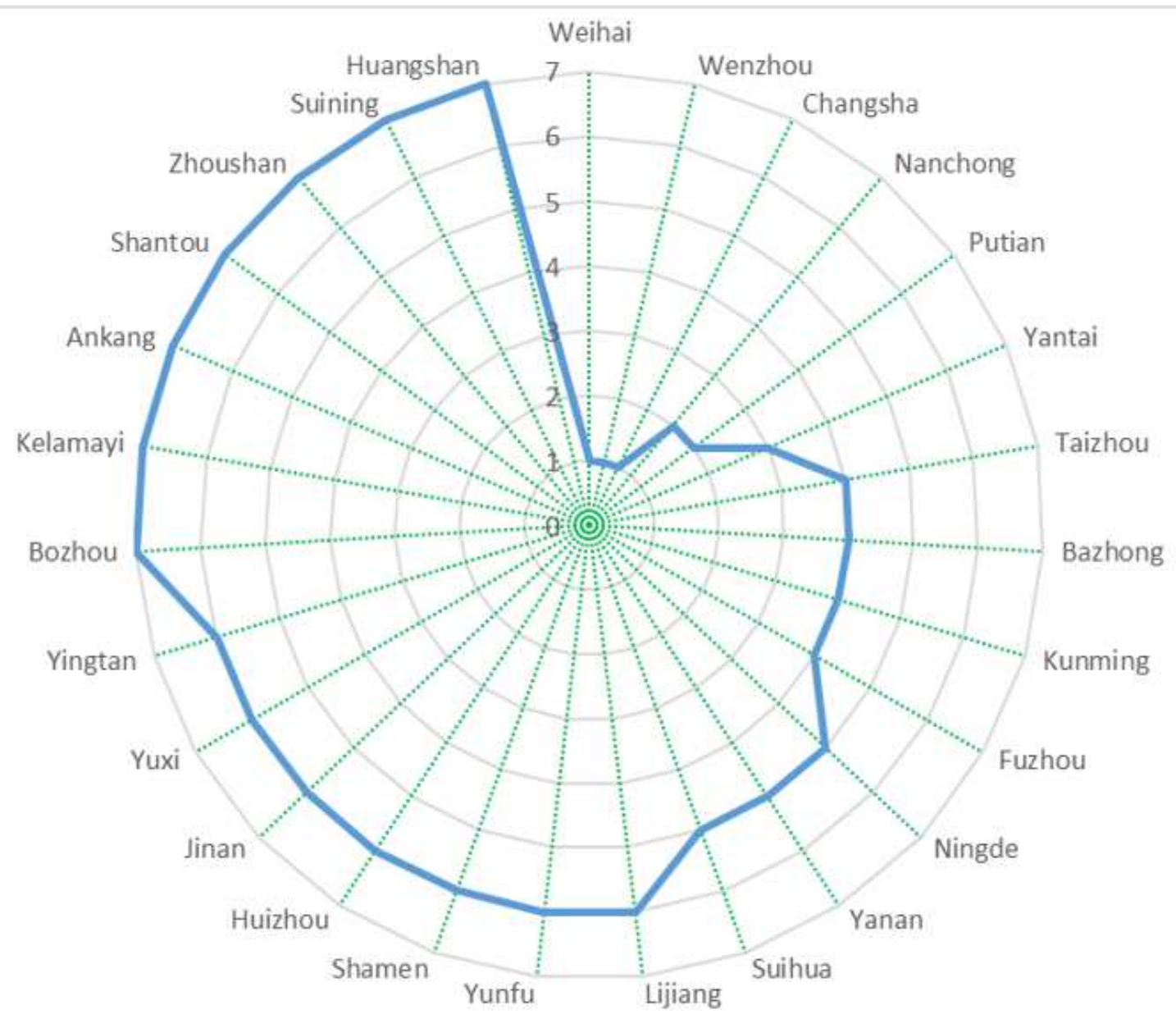




\section{Figure 4}

Numbers of years in which ER was greater than the threshold in the cities which less than 8 from 2004 to 2016. 